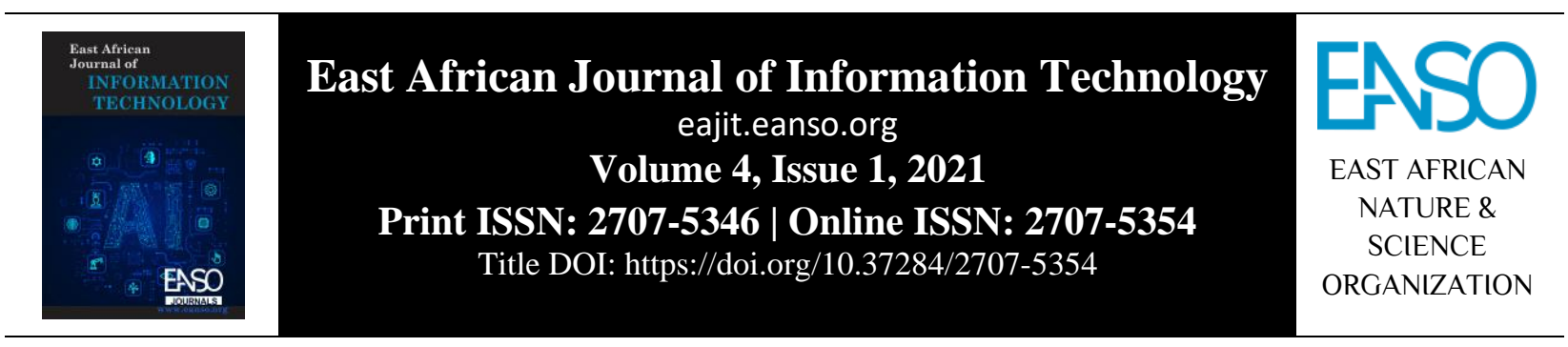

Original Article

\title{
An Analytical Review of Existing Supermarket Billing Systems.
}

\author{
Gilbert Gilibrays Ocen, PhD ${ }^{1}$, Semwogerere Twaibu, PhD $^{1 *}$, Sekamwa Umar ${ }^{1}$ \& Matovu Davis ${ }^{1}$ \\ ${ }^{1}$ Busitema University, P. O. Box 236, Tororo, Uganda. \\ * Correspondence ORCID: https://orcid.org/0000-0002-7276-844; email: tsemwogerere@eng.busitema.ac.ug.
}

Article DOI: https://doi.org/10.37284/eajit.4.1.440

\section{Date Published: ABSTRACT}

26 November 2021 Retail shops and stores form part of the nation's business sector involved in selling and providing several goods and services. The main objective was to

Keywords: study and analyse existing supermarket billing systems and possibly identify their weaknesses and strengths. This will enable us to generate an RFID

Billing System, billing system that is unique and even more advantageous than the existing

Price, systems. The methodology used was qualitative involving hard and soft

Queues, document reviews and observational experiments. Findings revealed that

RFID, there are several billing systems which include the manual price tag system Supermarket. where a mini-computer (calculator) is used to sum up the total bill per customer at a time, the barcode reader system, the smart chart with store cards, and the 'smart shopping cart. It was noted that these have the advantage of giving confidence all the items are counted, paid for, save time and are cheap to use. However, they are also associated with several weaknesses like long waiting time (queues), the systems require a lot of human effort to read the barcodes which is not efficient, barcode systems sometimes fail to read, possible human errors while entering information, possible cheating through wrongly-fed information and the desynchronization effects because of the unreliable network. This was an awareness drive about the existing supermarket billing systems in order to enhance further studies on better ones.

\section{APA CITATION}

Ocen, G. O., Twaibu, S., Umar, S., \& Davis, M. (2021). An Analytical Review of Existing Supermarket Billing Systems. East African Journal of Information Technology, 4(1), 1-6. https://doi.org/10.37284/eajit.4.1.440

\section{CHICAGO CITATION}

Ocen, Gilbert Gilibrays, Semwogerere Twaibu, Sekamwa Umar, \& Matovu Davis. 2021. "An Analytical Review of Existing Supermarket Billing Systems". East African Journal of Information Technology $4 \quad$ (1), 1-6. https://doi.org/10.37284/eajit.4.1.440.

1| This work is licensed under a Creative Commons Attribution 4.0 International License. 
HARVARD CITATION

Ocen, G. O., Twaibu, S., Umar, S., \& Davis M. (2021) “An Analytical Review of Existing Supermarket Billing Systems”, East African Journal of Information Technology, 4(1), pp. 1-6. doi: 10.37284/eajit.4.1.440.

\section{IEEE CITATION}

G. O. Ocen., S. Twaibu., S. Umar., \& M. Davis. "An Analytical Review of Existing Supermarket Billing Systems”, EAJIT, vol. 4, no. 1, pp. 1-6, Nov. 2021.

\section{MLA CITATION}

Ocen, Gilbert Gilibrays, Semwogerere Twaibu, Sekamwa Umar, \& Matovu Davis. "An Analytical Review of Existing Supermarket Billing Systems". East African Journal of Education Studies, Vol. 4, no. 1, Nov. 2021, pp. 1-6, doi:10.37284/eajit.4.1.440.

\section{INTRODUCTION}

Supermarkets are large retail stores operated on a self-service basis selling food goods like; agriculture produce, beverages, meat, bakery and dairy products, and sometimes non-food goods like; appliances, utensils, groceries, electronics among others (Thomas, 2004). Supermarkets were first established in the U.S. during the 1930s as no-frills retail stores offering low prices. In the 1940s and 1950s, they became the major food marketing channel in the U.S; the 1950s also saw them spread through much of Europe (Elepu, 2008).

In Uganda, supermarkets have taken the lead in the retail business. These were identified among others: Shoprite, Game Stores, Uchumi, Nakumatt and Tuskys, Capital Shoppers, Quality Supermarket, and Kenjoy. Industry experts say the launch of a new supermarket, which operates alongside small and medium stores, comes with a lot of unfulfilled expectations for manufacturers and stiff competition in the market. However, they provide many employment opportunities, more revenue, quality products, and relatively cheaper commodities to the shoppers (Gwambe \& Businge, 2012).

Features associated with supermarkets include goods being exposed to the customers' view in the aisles together with their prices tagged on hence no bargaining. The customer is required to pick goods from the supermarket on a self-service basis, and then present them to the cashier at the exit counter for billing and packing (Gwambe \& Businge, 2012).

There are numerous advantages associated with supermarkets include (Hamlet, 2008): Prices of supermarket products are relatively low as compared to other retail shops; they provide a very convenient way of shopping where the shopper is provided with a variety of goods from which choice is made; Supermarkets support advanced means of payment like; cheque, credit card, smart store electronic card, mobile money, and cash; they also offer after-sales services like; packaging, transportation incentives, discounts, promotional goods among others.

The quality of goods purchased from supermarkets is relatively high and guaranteed (Hamilton, 2012). This is because every commodity is price-labelled together with its expiry date, manufacturer, supplier and they are subjected to regular monitoring and verification by the relevant Standards Boards. Some supermarkets offer a 24/7 shopping experience which allows shoppers access to goods at their own time of convenience. Supermarkets nowadays are crowded almost every hour of the day due to the increasing number of supermarket users in Uganda. Customers have to wait in long exit queues as the cashier checks out each commodity using a barcode reader or a price tag, and then sends them to the counter assistant for packing before they are given to the customer. This leads to wastage of valuable customer time in supermarket queues.

Therefore, the main objective of the study was to review and analyse existing supermarket billing systems and possibly identify their weaknesses and strengths. This will enable us to recommend alternatives like an RFID billing system that is unique and even more advantageous than the existing systems.

\section{METHODS AND MATERIALS}

\section{Document Review}

This included reading textbooks, journals, magazines, and newspapers plus making good use 
of the available internet facilities. It also provided a wide knowledge base of the different supermarket billing systems.

\section{Observation}

A close look at how people interact with supermarkets and how convenient they find them was made. There was the need to ascertain how all stakeholders in the supermarket business e.g., cashiers, customers, owners, managers find the current billing system and the future perspective they have towards the billing systems used apparently. Observation also involved ascertaining the approximate amount of time it takes a cashier to bill an average customer in order to compare the values to the developed system.

\section{Data Analysis}

The data collected was analysed based on the objective specified in this study. A qualitative approach was used and the consistency of the data was ensured to come up with effective recommendations. This was achieved by coming up with a context diagram. After collecting and interpreting all the relevant information, a documentation report with all the findings and challenges met was formed intended to help any other person who might be capable and interested in enhancing or improving the performance of the system to be developed.

\section{FINDINGS AND DISCUSSION}

\section{Existing Supermarket Billing Systems}

Current systems in Uganda require that the customer enters the supermarket, pick whatever they want from the supermarket and present them to the cashier for billing at the counter. According to a survey conducted by the US Bureau of Labor, on average, human beings spend 1.4 hours everyday shopping especially in supermarkets and shopping malls (Luthur, 2005). According to a study conducted by CISCO Internet Business Solution Group, the top four reasons for shoppers to use supermarkets are to; find the best price (63\%), save time (47\%), find the best assortment (26\%), and find best quality (25\%) (Armstrong, 2011).
The growth of supermarkets is a phenomenon that characterizes many developing countries. The growth of supermarkets in Uganda can be attributed to the country's favorable investment or political climate. This is coupled with the increase in supermarket demand factors such as the rise in urbanization, the growth of the middle class, and the increase in the number of employment opportunities (Elepu, 2008). This growing number of supermarkets has led to a big percentage of people in Uganda resorting to using supermarkets for shopping than the other shopping centers because of the better services provided. The current Shopping environment can simply be classified into two categories; shopping in-person and shopping in absentia. Shopping in absentia is supported in numerous ways including online shopping and teleshopping among other things, wherein a shopper does not have to be physically present in the shopping area. Shopping in-person involves customers entering the supermarket and selecting the commodities they want on a self-service basis (Stuart, 2007). These commodities are then presented to the counter for billing and packaging. At the counter, some supermarkets have barcode readers that help cashiers in carrying out the billing by reading the special bar codes tagged on each commodity. While in others, attendants use a manual way with the help of their eyes to check the price tags on the items and feed those prices into the calculator to get the total cost of things purchased by a particular customer (Hamlet, 2008).

The available systems present a large number of shoppers in queues at the exit counters as they wait for their items to be tallied hence wastage of customers' time (Goldman, 2013). A survey report by Leonard, (2005), points out that $70 \%$ of the customers will walk out of the queue if it is too long, and $10 \%$ are "seriously annoyed" the moment they step in a queue (Leonard, 2005). Long customer queues can lead to dissatisfied customers and lost businesses thus need to take measures to reduce queues and improve operation. A study by A. Goldman revealed that how well queues are managed in the service industry can have a tremendous impact on customer service since nobody enjoys waiting in long lines (Goldman, 2013). Just like in business, time is precious hence need to understand the impact of queues and the effect they have on customers and business. The

$3 \mid$ This work is licensed under a Creative Commons Attribution 4.0 International License. 
proposed system will be able to reduce these long queues by eliminating the time wasted at the billing counter as cashiers try to count items per item and in packing the items.

\section{Manual Price Tag System}

In this system, the supermarkets use price tags. The cashier is required to read the prices from the price tags attached to commodities and feed them into a calculator or computer to generate the total cost (Smith, 2011). When all the items have been counted, the customer is then told the amount of money to pay, and a receipt is issued. The items are packed into shopping bags and the customer leaves the counter table creating room for the next customer in the exit queue to also go through the same process.

\section{Barcode Reader System}

In this system, a POS station terminal is installed at the checkout counter of the supermarket. A bar-code scanner for reading a bar-code label attached to every item is connected to the POS station terminal using a cable. The CPU contained in the POS station terminal processes the data read by the bar-code reader and controls other devices attached to it like; keyboard, display, printer, etc. (Rouse, 2011; Smith, 2011; Li et al., 2010).

The bar-code reader comprises a light source that emits a laser beam, an optical device that receives light reflected from a bar-code label and converts it into an electrical signal, and a converter that performs conversion to bar-code data based on the electrical signal.

When billing a purchased item, the cashier brings the bar-code label attached to the purchased item into the reading area of the optical device. Thereupon, the optical device receives light reflected from the bar-code label, then this optical signal is read and converted into a digital form within the bar-code reader, and the resulting barcode data is decoded (Motohiko, 2003; Lindsay, 2003).

When the thus read bar code is identified as the first barcode which is completely read, the bar-code reader transmits the bar-code data to the POS station terminal for billing. At this time, a speaker contained in the bar-code reader produces a short beep tone signifying that the bar-code data has been transmitted to the POS station terminal.

The bar-code reader is equipped with a doublereading-prevention timer to prevent the same barcode data from being read during a predetermined period of time (Motohiko, 2003; Li, 2010; Ferguson, 2006). This system is used in quite a big number of supermarkets in Uganda.

\section{Smart Chart with Store Cards}

The smart shopping trolley contains an interactive screen and a store card scanner mounted on it. Once the shopper swipes his store card, his shopping history is availed for all kinds of purposes including; suggested shopping list, discounts, or reminding the shopper about perishables purchased a month ago. If the customer scans the purchases for selfcheckout at the counter, the system automatically deducts the total cost for the goods purchased (Hawthorne, 2013; Lindsay,2003).

This system however raises concerns about the privacy of the shoppers since their shopping details are stored on the store card (Stuart, 2007). This system also requires a customer to be shopping from the same supermarket to keep records of all the previous shopping which limits his/her choice.

\section{Smart Shopping Cart for Supermarkets}

The system is a smart shopping cart that is able to capture every item put in the customer's cart and display the price and weight of the item scanned (using a barcode reader) on the screen mounted on the cart (LCD). It is capable of interacting with the database of the supermarkets to pick the required information. Each cart has a number that is stored in the database and is used at the counter to access the window containing items that have been scanned and dropped in that particular Cart. Multi-tasking at the server is done in case multiple Carts are in use so that each cart displays the right billings to the respective customer's cart screen. All carts are powered and always connected to the database on a working day. Cart's details can only be accessed once the customer places an end shopping button showing that the customer is ready to pay and leave the supermarket (Gary, 2006).

4 | This work is licensed under a Creative Commons Attribution 4.0 International License. 


\section{Strength of the Existing Systems}

Existing systems still give confidence to the cashier to some good extent, that all the items taken by the customer have been counted and paid for. They are also cheap in terms of purchase of tools used (Csipak, 2014).

\section{Weakness of the Existing Systems}

Barcode readers and manual price tags systems have the following weaknesses;

The system creates long waiting times (queues) at the counter as the customers wait to be worked on by the cashier. This is because the cashier is required to count item per item in the shopping cart while capturing the prices (Lawrence, 2013). More time is also wasted at the billing counter as counter assistants pack the items into shopping bags before the customers make their exit (Lawrence, 2013; Andrew, et al, 2006).

Both systems require a lot of human effort to read the barcodes which are not efficient (Gary, 2006). The barcode system is prone to making errors as some barcodes fail to be read due to moisture, liquids, and scratches (Lawrence, 2013). Human errors are also inevitable in the price tags system, since the cashier may miss out on a single digit causing considerable loss to the supermarket. Some cashiers take advantage of these systems to cheat customers by exaggerating prices since customers are not given the chance to verify the total bill.

The Smart Shopping Cart on the other hand has several weaknesses which include among others: It uses wireless communication to synchronize with the database. This is unreliable for the case of Uganda supermarkets because of the reliability of the internet and other favorable factors like literacy. More so, the charts require constant powering even when they are dormant, this is very costly coupled with unreliable power. It also employs barcode readers which themselves are associated with a number of challenges as earlier seen.

The system is prone to making errors since many charts can approach the counter at the same time hence interference in communicating with the database server. Shoppers can also cheat the supermarket by inserting goods unpaid for into the chart.

\section{CONCLUSION}

It was noted that the existing systems pause long waiting times (queue) to customers at the exit counter as cashiers capture items per item in the customer's trolley. To minimize this problem, an automated supermarket self-billing system is proposed and recommended in this study. Its design involves a composition of a hardware system, a database module, and two user interface modules. The hardware module is responsible for interfacing with the commodities bought by reading the tags and sending their unique identification numbers to the user interface and database. The database module contains updated information about all the commodities available in the supermarket at a given time. The user interface module interfaces the system to the users i.e., Cashier and Customer, this is through displaying the list of commodities bought on the cashier's PC, providing provisions for sending commands to the system, and also indicating the total amount to be paid to the customer. It is also expected to notify the users about the on-going activities by giving a beep sound, LED blink indication, and a display of the total on the LCD. The system is expected to contain these hardware components: Arduino Board, RFID Reader, the LCD, Electronic Components, Buzzer and LED. These are expected to assist in the coordination of activities, reading the RFID tags on commodities, display of information, connecting, regulating, and directing current in the system, signalling, and alerting among others.

\section{REFERENCES}

Andrew, S. W., Rome, F. A. O., \& Gálvez, E. (2007). The response of traditional marketing channels to the growth of supermarkets and to the demand for safer and higher quality fruit and vegetables, with particular reference to Asia. Lotus Pang Suan Kaeo Hotel, Chiang Mai, Thailand, 304.

Armstrong, A. (2011). Reasons for Using Supermarkets. Cancas United States: CISCO Internet Business Solution Group. 
Csipak, J. J., Rampal, R., \& Josien, L. (2014). The effect of a Wal-Mart supercenter on supermarket food prices: The case of the city of Plattsburgh in upstate New York. Academy of Marketing Studies Journal, 18(2), 251.

Elepu, G. (2008). The growth of supermarkets and its implications for smallholders in Uganda.

Ferguson, R. B. (2006). Wal-Mart's CIO Dishes on RFID at NRFTech Conference. E-Week. com.

Gary A. Smith, M. D. (2006). Shopping CartRelated Injuries to Children. American Academy of Pediatrics.

Goldman, A. (2013). Retrieved from Managing Queues in the Service Industry, 25 $5^{\text {th }}$, October, 2013.

Gwambe, T., \& Businge, J. (2012, May 05). Blossoming Supermarkets. The Independent, pp. 9-10.

Hamilton, S. (2012). Supermarkets, Free Markets, and the Problem of Buying Power in the Postwar United States, in What's Good For Business: Business and Politics Since World War II, ed. Julian Zelizer and Kim Phillips-Fein (Oxford University Press, 2012).

Hamlet, J. (2008). "Regulating the UK Supermarkets: An Oral-Historical Perspective". United Kingdom: History \& Policy. Archived from the original on 7 August 2011. Retrieved 9 December 2010.

Hawthorne, N. A. (2013). Smart Carts, Veggie Vision in Grocery Stores to come, 26 ${ }^{\text {th }}$, September, 2013.

Lawrence, M. (2013, August 27). Disadvantages of Barcodes use in Supermarkets.

Leonard, T. (2005). Impact of Queues on Customers. Newyork: Visa.

Li, S., Godon, D., \& Visich, J. K. (2010). An exploratory study of RFID implementation in the supply chain. Management Research Review.
Lindsay, W., \& Reade, J. (2003). RFID Systems for Enhanced Shopping Experiences. article dated Nov, 10.

Luthur, A. (2005, May 3). American Time Use Survey. Echaria, pp. 20-22.

Motohiko, I. K. M. (2003, March 4). Patent No. US 6,527,179 B1. United States Patent.

Rouse, M. (2011, March). Barcode reader (POS scanner, bar code reader, price scanner).

Smith, P. (2011, July 11). The History of the Supermarket Barcodes. Blogspot. 34.

Stuart, A. (2007, August 27). Cisco Internet Business Solution Group survey document, My Shopping. Newyork: NYTP.

Thomas, R., Timmer, C. P., \& Berdegué, J. A. (2004). The rapid rise of supermarkets in developing countries: induced organizational, institutional, and technological change in agrifood systems. eJADE: Electronic Journal of Agricultural and Development Economics, 1(85 3-2016-56108), 168-183.

6| This work is licensed under a Creative Commons Attribution 4.0 International License. 